\title{
The effect of auditory stimulation on responses to tactile stimuli
}

\author{
GEORGE A. GESCHEIDER, MARTIN J. KANE \\ and LAWRENCE C. SAGER \\ Hamilton College, Clinton, N.Y. 13323 \\ and \\ LYDIA J. RUFFOLO
Kirkland College
}

The detectability of a $500-\mathrm{Hz}$ sinusoidal vibration on the fingertip lasting $1 \mathrm{sec}$ was only slightly affected by simultaneously presenting a moderately intense auditory stimulus of the same frequency. However, both hit and false alarm rates for detecting tactile stimuli were significantly higher on tone than on no-tone trials. This finding, coupled with the finding that magnitude estimations of tactile stimuli were higher on tone than on no-tone trials, was interpreted as support for the hypothesis that auditory stimulation can facilitate neural activity in the tactile sensory system.

When a Békésy threshold-tracking method was employed, tactile thresholds for brief mechanical pulses to the index fingertip were raised as much as $5 \mathrm{~dB}$ by simultaneous presentation of a 90-dB SL auditory click (Gescheider \& Niblette, 1967; Gescheider, Herman, \& Phillips, 1970). However, threshold measurements obtained by classical psychophysical procedures, including the Békésy tracking method, are affected by changes in O's decision criterion as well as by changes in stimulus detectability. When the contaminating effects of criterion shifting were eliminated by using a forced-choice procedure (Gescheider, Barton, Bruce, Goldberg, \& Greenspan, 1969) or a modified tracking procedure (Gescheider et al, 1970), the tactile threshold elevation produced by the click was only about $1.8 \mathrm{~dB}$.

The purpose of the present experiment was to measure the detectability of a $500-\mathrm{Hz}$ sinusoidal vibration on the fintertip lasting $1 \mathrm{sec}$ when a moderately intense tone of the same frequency is simultaneously presented and when it is absent. The degree of attention to the auditory stimulus was varied by either instructing $\mathrm{O}$ to attempt to ignore the tone or by having him make a loudness recognition response to it. It was expected that the detectability of the tactile stimulus would be about the same when no tone was presented as when an unattended tone was presented, but would be greatly reduced when the $O$ was required to attend to the tone.

\section{METHOD}

\section{Observers}

The Os were one female and four male undergraduate students. Each $\mathrm{O}$ was trained for not less than five 1-h sessions in detecting tactile stimuli and in recognizing auditory stimuli that differed slightly in intensity.

\begin{abstract}
Apparatus
Sinusoidal electrical signals generated by a General Radio 1304-B oscillator were applied to a Grason-Stadler $829 \mathrm{E}$ electronic switch to give a $500-\mathrm{Hz}$ signal lasting $1 \mathrm{sec}$, with a rise and decay time of $25 \mathrm{msec}$. The output of the electronic switch was applied to a Grason-Stadler E3520B phase shifter adjusted to provide two independent signals in phase when applied to a Goodmans V-47 vibrator and a pair of Permoflux PDR-600 earphones. In each of the two channels, signal strength was manipulated by a decade attenuator box placed between the output of the phase shifter and the transducers. An impedance matching transformer was placed between the attenuator and the vibrator.

In a small audiometric testing room, $O$ made judgments of the presence or absence of the vibrotactile stimulus on his right index fingertip. The $O$, resting his right hand on a table, placed his index fingertip on a vibrator contactor that was $6.5 \mathrm{~mm}$ in diam. A $1-\mathrm{sec}$ observation interval was indicated to the 0 by turning on and off a small white light. The O's task was to judge the presence or absence of the tactile stimulus following the observation interval. On some trials, an 80 - or $82-\mathrm{dB}$ SPL, $500-\mathrm{Hz}$ tone was presented binaurally during the observation interval and $O$ had to report whether the tone was high or low after making his tactile judgment. The $O$ made his yes-no tactile response and his high-low auditory response by closing two bidirectional telephone switches. An observation interval was presented every $4 \mathrm{sec}$. Knowledge of results was given to $\mathrm{O}$ after each response through lights mounted near the observation interval light. The stimulus events in a series of observation intervals were programmed by a Tally $\mathrm{R}-50$ tape reader.
\end{abstract}

\section{Procedure}

The probability of a tactile stimulus was .5 during each session. Preliminary to each session, O's sensitivity was determined and vibration amplitude was set at a value that would result in $\mathrm{d}^{\prime}$ values between 1.0 and 2.0 for the experimental trials. Each of the eight sessions was divided into four blocks of 240 trials, within which $O$ performed one of the following four tasks: detection of tactile stimuli (Task A); detection of tactile stimuli and recognition of the loudness of tones (Task B); detection of tactile stimuli accompanied by a tone (Task C); and recognition of the loudness of tones (Task D). The order of the four tasks within a session was counterbalanced over the eight sessions. On blocks of trials in which auditory stimuli were presented, the probability of a tone was .5 and was independent of the probability of a tactile stimulus presentation. Half of the tones were $80 \mathrm{~dB} \mathrm{SL}$ and half were $82 \mathrm{~dB} \mathrm{SL}$. The independence of tactile and auditory stimulus presentations was stressed to $O$ at the start of the experiment. When $\mathrm{O}$ made a yes-no judgment of the tactile stimulus, he also made a confidence rating. He was instructed to report "five" when he was sure the stimulus had been presented, "four" when he was fairly sure the stimulus had been presented, "three" when he was not sure, "two" when he was fairly sure no stimulus had been presented, and "one" when he was sure no stimulus had been presented.

\section{RESULTS}

The values of d', a measure of O's sensitivity, and $\beta$, a measure of his decision criterion, were calculated for performance in detecting tactile stimuli in Tasks A, B, 
Table 1

Mean Values of $d^{\prime}, \beta$, Hit Rate, False Alarm Rate, and Percentage of Correct Responses in Detecting Tactile Stimuli in the Presence of and in the Absence of Auditory Stimulation

\begin{tabular}{|c|c|c|c|c|c|}
\hline & \multicolumn{5}{|c|}{ Task During Blocks of 240 Trials } \\
\hline & \multirow{3}{*}{$\begin{array}{c}\frac{\text { Task A }}{\text { Detect }} \\
\text { Vib } \\
\end{array}$} & \multirow{2}{*}{\multicolumn{2}{|c|}{$\begin{array}{c}\text { Task B } \\
\begin{array}{c}\text { Detect Vib } \\
\text { Judge Tone }\end{array}\end{array}$}} & \multirow{2}{*}{\multicolumn{2}{|c|}{$\begin{array}{c}\text { Task C } \\
\begin{array}{c}\text { Detect Vib } \\
\text { Tone }\end{array} \\
\end{array}$}} \\
\hline & & & & & \\
\hline & & $\mathrm{Vib}$ & Vib-Tone & Vib & Vib-Tone \\
\hline $\begin{array}{l}\mathrm{d}^{\prime} \\
\beta \\
\text { Hit Rate } \\
\text { FA Rate }\end{array}$ & $\begin{array}{l}1.74 \\
1.30 \\
.722 \\
.176\end{array}$ & $\begin{array}{l}1.98 \\
1.35 \\
.754 \\
.149\end{array}$ & $\begin{array}{l}1.88 \\
.93 \\
.797 \\
.231\end{array}$ & $\begin{array}{l}1.94 \\
1.43 \\
.740 \\
.144\end{array}$ & $\begin{array}{l}1.93 \\
.95 \\
.801 \\
.217\end{array}$ \\
\hline $\begin{array}{l}\text { Percent } \\
\text { Correct }\end{array}$ & 77.3 & 80.3 & 78.3 & 79.8 & 79.2 \\
\hline
\end{tabular}

and $\mathrm{C}$. The values of $\mathrm{d}$ 'were calculated from Theodor's (1972) equation:

$$
\mathrm{d}^{\prime}=\sigma_{\mathrm{SN}} / \sigma_{\mathrm{N}} \mathrm{z}_{(\text {hits })}-\mathrm{z}_{(\text {false alarms })}
$$

The value of $\sigma_{S N} / \sigma_{N}$, the ratio of the standard deviations of the signal plus noise and noise distribution, was estimated to be 1.37 from the reciprocal of the slope of the ROC curves that were constructed from the confidence rating data (see Green \& Swets, 1966, pp. 40-43).

As seen in Table 1, contrary to expectation, tactile sensitivity was poorest $\left(\mathrm{d}^{\prime}=1.74\right)$ during blocks of trials in which tones were never presented (Task A). In fact, the percentage of correct responses in Task A was significantly lower than the percentage of correct responses on tone and on no-tone trials in Task $\mathrm{C}$ and no-tone trials in Task B. However, for blocks of trials in which $\mathrm{O}$ had to judge tones as well as detect tactile stimuli (Task B), tactile sensitivity was slightly lower on tone trials $\left(\mathrm{d}^{\prime}=1.88\right)$ than on no-tone trials $\left(\mathrm{d}^{\prime}=1.98\right)$. The differences between the percentages of correct responses was significant at the .05 level. For blocks of trials in which tones were presented but not judged (Task $\mathrm{C}$ ), sensitivity to tactile stimulation was essentially the same on tone trials $\left(\mathrm{d}^{\prime}=1.93\right)$ as on no-tone trials $\left(\mathrm{d}^{\prime}=1.94\right)$.

Each value of $\beta$ presented in Table 1 was estimated by converting the proportion of hits and false alarms into ordinate units of the normal curve and dividing the ordinate value for the hits by the ordinate value for the false alarms. For both Tasks B and C, the presentation of a tone produced a statistically significant increase in hit and false alarm rates, which caused a reduction of the value of $\beta$.

The proportion of correct auditory judgments was significantly higher for Task $D$ in which only tones were presented (.783) than for Task B in which $O$ had to detect tactile stimuli and also judge tones (.712).

\section{DISCUSSION}

It appears from the results that tactile sensitivity is not adversely affected by the presence of a simultaneous auditory stimulus. In fact, presenting an auditory stimulus on a random schedule within a block of trials seems to slightly facilitate tactile performance on both tone and no-tone trials. Perhaps, under these conditions, auditory stimulation slightly increases general arousal, which in turn increases information processing efficiency. The slightly lower performance in Task B on tone than on no-tone trials may have been due to reduced attention to tactile information. That the effect is small may suggest many possibilities for the design of cutaneous communication systems in which auditory recognition of simple stimuli must occur during cutaneous information processing.

Performance on the auditory task was somewhat disrupted by requiring $\mathrm{O}$ to also perform a tactile stimulus detection task. In Task B, $O$ made an auditory response after making a tactile response, while in Task $\mathrm{D}$, he made the auditory response immediately after the auditory stimulus. Consequently, some of the factors that could have caused disruption of auditory performance in Task B are: (a) the enforced delay between stimulus and response; (b) the interpolated tactile response; and (c) reduced attention to the auditory stimulus because of attention requirements in the tactile task.

The most interesting effect the tone had on tactile performances is seen not in large changes in tactile sensitivity, but rather in a substantial reduction in the value of $\beta$. One possible interpretation of this finding is that the presentation of the tone induced $\mathrm{O}$ to change his decision criterion to a point lower on the sensory magnitude continuum, resulting in an increase in both hit and false alarm rates. None of the Os, however, reported being aware of using such a decision strategy, but instead consistently reported that the tone seemed to increase the intensity of tactile sensations on both $\mathrm{N}$ and $\mathrm{SN}$ trials. Thus, the second, and more plausible, interpretation of the results is that the tone facilitates neural activity in the tactile sensory system, resulting in a shift in the location of $\mathrm{N}$ and $\mathrm{SN}$ distributions to points higher on the tactile sensory magnitude continuum. Since both distributions are affected almost equally, $\mathrm{d}^{\prime}$ remains about the same while the hit and false alarm rates increase. This hypothesis is consistent with the finding that the decrease in $\beta$ on tone trials was independent of whether or not $\mathrm{O}$ had to judge the tone.

An experiment was conducted in which three Os made three magnitude estimations for each of eight amplitudes of a $500-\mathrm{Hz}$ vibrotactile stimulus applied to the fingertip for $1 \mathrm{sec}$ in the

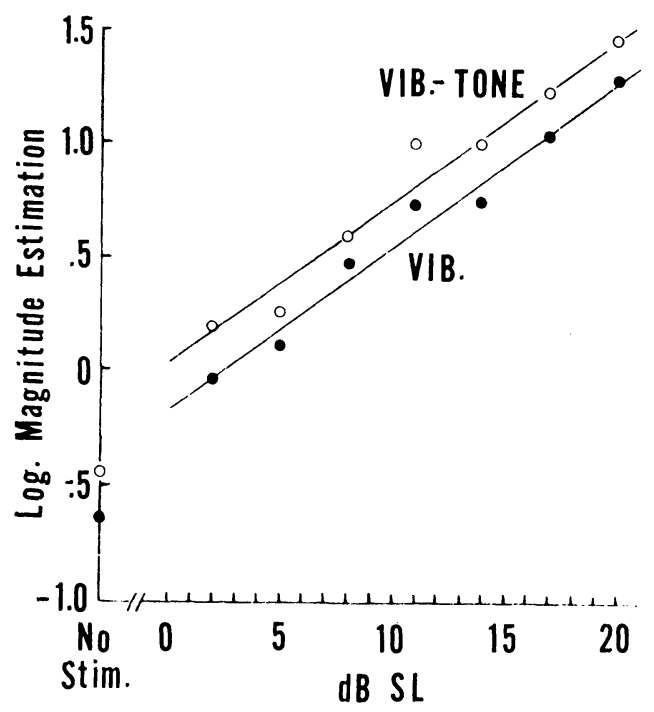

Fig. 1. Logarithm of the geometric mean of magnitude estimations as a function of vibration amplitude in $\mathrm{dB}$ SL when the tone was presented with the tactile stimulus and when it was not. 
presence of and in the absence of a 1-sec, 80-dB tone of the same frequency. Each data point in Fig. 1 is the geometric mean of the three Os' results. Two sensation magnitude functions were fitted to the data by the method of least squares. The finding that magnitude estimations for all amplitudes of the tactile stimulus, including zero amplitude, were higher when the tone was presented than when it was not presented supports the hypothesis that a brief auditory stimulus presented simultaneously with a tactile stimulus can enhance tactile sensations.

It should be pointed out, however, that sensory interaction as psychophysically measured is a labile phenomenon. The experimental procedure may have a variety of effects on the $O$. As determined by previous studies, auditory stimulation may change tactile sensitivity and it may induce $O$ to change his decision strategy. The results of the present study suggest that auditory stimulation may also change both the signal level and the noise level in the tactile sensory system, leaving sensitivity unchanged.

\section{REFERENCES}

Gescheider, G. A., Barton, W. G., Bruce, M. R., Goldberg, J. M., \& Greenspan, M. J. The effects of simultaneous auditory stimulation upon the detection of tactile stimuli. Journal of Experimental Psychology, 1969, 81, 120-125.

Gescheider, G. A. Herman, D. D., \& Phillips, J. N. Criterion shifts in the measurement of tactile masking. Perception \& Psychophysics, $1970,8,433-436$.

Gescheider, G. A., \& Niblette, R. K. Cross-modality masking for touch and hearing. Journal of Experimental Psychology, $1967,74,313-320$.

Green, D. M., \& Swets, J. A. Signal detection theory and psychophysics. New York: Wiley, 1966.

Theodor, L. H. A neglected parameter: Some comments on "A table for calculation of $d^{\prime}$ and $\beta$." Psychological Bulletin, $1972,78,260-261$.

(Received for publication November 9, 1973.)

\title{
Reinforcement relation: Reversibility within daily experimental sessions
}

\author{
JOSÉ J. BAUERMEISTER \\ University of Puerto Rico, Rio Piedras, Puerto Rico 00931 \\ and \\ ROBERT W. SCHAEFFER \\ Auburn University, Auburn, Alabama 36830
}

\begin{abstract}
Running and licking response probabilities in rats were obtained for the first and last 13-min periods of 30-min daily test sessions. When licking was the more probable response, it reinforced running; when running was the more probable response, it reinforced licking. These data confirm the relative and reversible properties of the reinforcement relation.
\end{abstract}

Premack (1965, 1971) has conceptualized reinforcement as a relative relation between responses. This view contrasts with the traditional concept of reinforcement in which responses are classified absolutely as either reinforcing or nonreinforcing. A corollary of Premack's relativity hypothesis, that the reinforcement relation is reversible, was supported in an experiment with rats where differential probabilities of running and licking were produced, then subsequently reversed by manipulating the $\mathrm{Ss}^{\prime}$ accessibility to an 